\title{
Una herida abierta. Tensiones y contrapuntos discursivos en Dos veces junio y Ciencias morales, de Martín Kohan.
}

\author{
An Open Wound: Tensions and Discursive Counterpoints \\ in Dos veces junio and Ciencias morales, by Martín \\ Kohan.
}

\section{Resumen}

El presente trabajo busca indagar acerca de los modos en los que operan las tensiones y contrapuntos discursivos en Dos veces junio (2002) y Ciencias morales (2007), de Martín Kohan. Para ello, se toman como punto de partida los diversos sentidos en pugna que atraviesan ambas novelas en relación con la norma impuesta y su transgresión, el discurso oficial y el marginal, lo manifiesto y lo velado, con el objetivo de identificar y analizar cómo se configuran las estrategias textuales que el autor pone a funcionar en su escritura, reinterpretando en clave literaria las tensiones sociales experimentadas durante la última dictadura cívico-militar en Argentina.

Palabras claves Kohan, tensiones, contrapuntos, discurso oficial, marginalidad, dictadura militar.

\begin{abstract}
This article seeks to inquire about the ways in which tensions and discursive counterpoints operate in Dos veces junio (2002) and Ciencias morales (2007), by Martin Kohan. We attend to take as point of departure the struggling senses that show up in both novels related to imposed regulations and their transgressions, official discourses and marginal ones, the exhibited and the veiled, pursuing the goal of identifying and analyzing how the author configures the textual strategies that he uses in his writing to literary reinterpret the social tensions experienced during the last civic- military dictatorship in Argentina
\end{abstract}


CATEdral Tomada: Revista de crítica literaria latinoamericana / Journal of Latin American Literary Criticism Una herida abierta. Tensiones y contrapuntos discursivos en Dos veces junio y Ciencias morales, de Martín Kohan.

Keywords Kohan, tensions, counterpoints, official discourse, marginality, military dictatorship.

Dos veces junio (2002) y Ciencias morales (2007), de Martín Kohan, forman parte de la serie de novelas de la posdictadura argentina que recuperan el contexto del autodenominado "Proceso de Reorganización Nacional", operando como ficciones interrogativas de lo real (Sarlo 42) y como relecturas de un pasado reciente que aún constituye una herida abierta para el país. Ambas obras recrean no sólo experiencias y vivencias de una época oscura y opresiva, sino también un clima sugestivo en el que el lector intuye un conjunto de sentidos que intentan emerger de lo oculto. Se trata de los ecos del enfrentamiento entre el discurso autoritario y el de la disidencia, pugna que da lugar a tensiones sociales que Kohan reinterpreta en clave literaria, poniéndolas a funcionar como mecanismos textuales articuladores de la estructura ficcional.

Las dos novelas tejen un entramado en el que confluyen la ubicuidad del adoctrinamiento y la rebeldía de lo subalterno, generando un contrapunto discursivo entre la norma impuesta (moral, social, institucional) y su transgresión, el discurso oficial y el marginal, lo manifiesto y lo velado, en una dinámica que teje múltiples referencias vinculadas al contexto sociohistórico de la dictadura de manera oblicua. En efecto, estas tensiones responden a un trasfondo en el que el ocultamiento, la clandestinidad y las resonancias del régimen militar, con su accionar y sus efectos, ponen en cuestión los modos tradicionales de narrar, complejizando el dispositivo textual y objetando el estatuto unívoco de los registros para dar lugar a un dialogismo (Bajtin, Problemas) en torno a la palabra y el silencio, lo dicho y lo no dicho, lo visible y lo oculto, lo liberado y lo reprimido, lo literal y lo figurado, lo presente y lo ausente. Como sugiere Sarlo en "Ficción y política: la narrativa argentina durante el proceso militar", lejos de suponer una postura maniquea, estos binarismos habilitan un espacio discursivo abierto en el 
que la densidad de significados abre el juego a la interpretación y la disputa de sentidos (43). ${ }^{1}$

Las dos narrativas de Kohan se encuentran atravesadas por acontecimientos históricos de gran relevancia que, insertos en la ficción, funcionan simultáneamente como maniobras de distracción y cohesión social frente a los problemas que aquejan al país, y como proyección textual de los mecanismos de ejercicio del poder de la dictadura, según analizaremos más adelante. En Dos veces junio el suceso en cuestión es el campeonato mundial de fútbol disputado en Argentina en el año 1978, mientras que en Ciencias morales, de manera subrepticia, es la Guerra de Malvinas acontecida entre el 2 de abril y el 14 de junio de 1982 (también presente en el epílogo de Dos veces junio). Estos hechos operan como marco sociohistórico tanto de los diversos sucesos narrados como de la línea argumental principal de cada una de las obras: la historia de un soldado conscripto que trabaja como chofer de un general de renombre mientras cumple con el servicio militar obligatorio y la de una joven preceptora del Colegio Nacional de Buenos Aires obsesionada con el acatamiento de las reglas, respectivamente.

Más allá de las diferencias en cuanto a la trama principal, los paralelismos de estas dos obras en relación con los ejes planteados son numerosos. Uno de los principales se vincula con la búsqueda del cumplimiento de la norma, en sintonía con la línea oficial según la cual "el orden de la Nación se propone como uno de los valores supremos" (Sarlo 37). En Dos veces junio, el protagonista se encuentra fuertemente influido por las reglas y el "deber ser", que surgen como imposiciones externas. Como puede observarse a medida que avanza el relato, son los pensamientos de sus referentes inmediatos los que permean en el narrador; su padre, quien le recordaba que "los milicos son gente de reglas claras" (Kohan, Dos veces

\footnotetext{
${ }^{1} \mathrm{Si}$ bien las apreciaciones críticas de la autora refieren a la literatura escrita durante la dictadura o en el período inmediatamente posterior a ella, existe una correspondencia entre los procedimientos textuales que analizaremos en el presente trabajo y los que caracterizaron a esas narrativas. Las estrategias literarias perduran, lo que se modifica es su intención: si en los 70 y 80 la literatura funcionaba como discurso de disidencia intelectual opuesto al autoritarismo dictatorial, en la actualidad se presenta como un espacio textual de reflexión, de denuncia y memoria que revisita esa época.
} 
CATEdral Tomada: Revista de crítica literaria latinoamericana / Journal of Latin American Literary Criticism Una herida abierta. Tensiones y contrapuntos discursivos en Dos veces junio y Ciencias morales, de Martín Kohan.

16) y, fundamentalmente, el Doctor Mesiano, vocero oficial del discurso castrense que impregna la novela. La suya, palabra autorizada para el protagonista, encarna la ideología dominante que concibe el orden marcial como única estrategia válida para combatir el caos presente desde los orígenes de nuestra historia: "dos fuerzas chocaron en la formación de la Argentina: una caótica, irregular, desordenada, la de las montoneras; otra sistemática, regular, planificada: la del ejército" (Kohan, Dos veces 37-38). Como señala el narrador, "los esquemas del Doctor Mesiano no admitían imprecisiones" (Kohan, Dos veces 105), puesto que una conducta sin fisuras supone el requisito fundamental para el ejercicio de la autoridad y el dominio. Esta vocación de disciplina, contagiada al conscripto durante su formación militar, lo convierte en un actor funcional al sistema, en una pieza más al servicio de un aparato estatal que sostiene su estructura en "la apreciada regularidad que nos permitía ser como engranajes de una máquina que nunca falla" (Kohan, Dos veces 45). En este sentido, el hábito y la costumbre son considerados valores fundamentales que el protagonista acata rigurosamente, cumpliendo a diario con un cronograma preestablecido y con horarios fijos para levantarse, bañarse, asear el auto del doctor Mesiano y pasarlo a buscar por su casa. Todas estas son manifestaciones de los mecanismos internos del poder que aseguran un control disimulado pero eficaz del día a día, basado en el sostenimiento de una sistematicidad constante bajo la premisa de que "en la vida, según decía el doctor Mesiano, todo es cuestión de método" (Kohan, Dos veces 43).

Método, regularidad y esquematismo son también los principios sistémicos que rigen el Colegio Nacional de Ciencias morales. Al igual que en Dos veces junio, la rutina del día a día contribuye a mantener el orden y el control. "Si hay algo que el colegio asegura, por encima de todo, es esta normalidad" (Kohan, Ciencias 29), comenta el narrador. En este contexto, el acatamiento del reglamento y el respeto a la autoridad son dos de los pilares que rigen el funcionamiento de una institución cuyo objetivo primordial es la ejemplaridad de las conductas. Para alcanzar este cometido, la vigilancia y la inspección actúan como mecanismos tendientes a lograr el cumplimiento de las obligaciones. El orden se convierte en un 
factor capital, incuestionable y definitorio del ideario escolar, ya que, como afirma el narrador, "las órdenes se dan una sola vez y con eso es suficiente" (Kohan, Ciencias 12). De este modo, el proceder del colegio se equipara notablemente con el del ámbito militar. Un ejemplo claro es el de la formación. Cuando se acomodan las filas y "el señor Biasutto da la orden de ponerse firmes" (Kohan, Ciencias 18), los alumnos deben responder con una pose rígida e inmutable. La figura del jefe de preceptores resulta similar a la del Doctor Mesiano, en tanto su mayor preocupación es la de impedir que se propague la amenaza del desorden, a la que compara con un cáncer. "En este tiempo, y en este colegio, es el espíritu de la subversión [el] que nos amenaza" (Kohan, Ciencias 19), afirma Biasutto, y, para lograr combatirla, la disciplina de los estudiantes debe ser tan modélica como la de los soldados. En definitiva, el colegio se erige como una suerte de microcosmos representativo de la nación: la referencia a "este tiempo", la rigurosa conducta que se exige a los alumnos y la puesta en voz de un discurso represivo, articulan el correlato entre la institución y el presente histórico, evocando el sistema despótico de imposiciones y restricciones del régimen dictatorial vigente en el país.

En su rol de preceptora, y como subordinada de Biasutto, María Teresa es la encargada de velar por la aplicación de las normas y el mantenimiento del orden. Si bien ella registra las faltas cometidas por los estudiantes, entre las que se encuentran contravenciones en el uniforme y en el corte de pelo, el desvío de la norma que pone en tensión el estatuto del orden a lo largo de la novela surge, paradójicamente, de su modo de actuar. En un intento por descubrir a los mayores infractores del Colegio, bajo la sospecha de que existen alumnos que fuman en el baño, la preceptora comienza una tarea de espionaje clandestina en el recinto (al modo de las que realizan los servicios de inteligencia del estado durante la dictadura) que se convertirá en su estímulo diario. Estas incursiones cada vez más frecuentes se transforman en una actividad cargada de sugestivo erotismo que pone en tensión tanto la norma moral (por espiar la privacidad de los alumnos) como la que rige su propio código de conducta en tanto autoridad escolar. Lo que en un principio parece constituir un afán por cumplir con las reglas, por lo que "importa 
CATEdral Tomada: Revista de crítica literaria latinoamericana / Journal of Latin American Literary Criticism Una herida abierta. Tensiones y contrapuntos discursivos en Dos veces junio y Ciencias morales, de Martín Kohan.

descubrirlos, importa denunciarlos, importa propiciar la estricta sanción que servirá de ejemplo" (Kohan, Ciencias 157), pronto se convierte en algo más; en "un impulso, vale decir un deseo repentino, un deseo del puro instante, aunque también le parece, no bien lo consuma, que este deseo venía germinando en ella desde hace algunos días" (Kohan, Ciencias 134). La cita en cuestión refiere a la decisión que toma María Teresa de orinar en el baño de varones junto con quienes acuden allí. Ese ímpetu cada vez más asiduo por concurrir al recinto, que la lleva a querer orinar en el lugar incluso cuando no se encuentra realizando sus secretas observaciones, marca otra de las fisuras en la norma. En este caso, más que de la incorrección o intento de transgresión de las reglas, la tensión nace de la inicial búsqueda de su aplicación a ultranza, convirtiéndose en una "combinatoria confusa de travesura, rebelión y puesta en orden" (Kohan, Ciencias 190) en la que María Teresa encuentra un espacio de liberación. El baño deviene refugio impenetrable en el que la preceptora se permite experimentar con lo prohibido, corrompiendo los límites de lo privado al convertir a los alumnos en objetos de un deseo floreciente que, en última instancia, combate la opresión externa. No obstante, las ataduras del régimen no ceden frente a este intento de evasión: la violación que el señor Biasutto ejerce sobre el cuerpo de la subordinada luego de descubrirla, se impone como castigo frente a una pulsión que no está permitida.

Otra puesta en entredicho de la norma -en este caso, de la lingüística- lo supone la falta de ortografía con la que ha sido escrito el interrogante que abre Dos veces junio: “¿A partir de qué edad se puede empesar a torturar a un niño?” (Kohan, Dos veces 11). La obsesiva actitud del narrador frente este error -"Pocas cosas me contrarían tanto como las faltas de ortografia" (Kohan, Dos veces 12), afirma- y su necesidad de corregirlo, ocultan un terrible trasfondo para el que resulta irrelevante el cumplimiento o no de la regla ortográfica, dando lugar a un contrapunto entre lo explícito y lo velado. Así, la incorrección gramatical implica la puesta en primer plano de un rasgo que desvía la atención del contenido de la pregunta, de aquello que debe permanecer oculto y no puede o, mejor dicho, "no debe" decirse. Este interrogante, que involucra una aberración, va de la mano con una respuesta elusiva 
que, por exceder los límites de la norma socialmente aceptada, se intenta callar. Por lo tanto, la focalización en el error gramatical intenta desviar la atención de la pregunta incómoda, profundizando la tensión aludida. Si bien este episodio parece mostrar al soldado como un sujeto cómplice y monolítico que acata ciegamente la autoridad, rigiendo sus acciones de acuerdo con las pautas predeterminadas por el sistema y sus referentes, la novela muestra también la contracara de esta realidad, en tanto los fragmentos interpolados que se solapan al conflicto medular funcionan como vías de escape en las que se filtran representaciones conceptuales y discursivas que difieren de la oficial. Se trata de datos, escenas, imágenes y anécdotas que intervienen el relato principal y lo complementan desde la marginalidad de una voz narrativa que coincide con la del protagonista. Estos fragmentos, aparentemente accesorios o irrelevantes, operan como manifestaciones alternativas al monologismo del aparato de control gubernamental, exhibiendo sus grietas. De esta manera, lo instituido y lo censurado se disputan de manera constante, y el corte se presenta como el mecanismo a partir del cual se entrelazan los sentidos en controversia. Un claro ejemplo lo constituye la reflexión fragmentaria acerca de los distintos tipos de balanza en "Dos trescientos", capítulo en el que, lateralmente, se discute acerca del peso que un niño debería tener para poder ser torturado. En el mismo sentido actúa la figura de la ominosa prostituta que mantiene relaciones sexuales con el protagonista, en tanto parece proyectar la de la madre del niño que motiva la pregunta de la tortura, mujer cautiva y vejada por sus interrogadores. El cuerpo de la prostituta se convierte en metonimia del acto sexual y, simultáneamente, del tormento físico: "un cuerpo desnudo que se entregaba sin reservas ni reticencias. Y, sin embargo, de ese cuerpo desnudo [...] no había manera de obtener una verdad. Se podía hacer lo que uno quisiera con el cuerpo resignado, excepto sacarle algo" (Kohan, Dos veces 99).

También resulta elocuente la obsesión numérica que circula en la novela. Los números no sólo dan título a los capítulos y a los fragmentos en que estos se dividen, sino que aparecen en múltiples ocasiones: el sorteo para la colimba, la formación de la selección de fútbol (se especifican el número de la camiseta, las 
CATEdral Tomada: Revista de crítica literaria latinoamericana / Journal of Latin American Literary Criticism

Una herida abierta. Tensiones y contrapuntos discursivos en Dos veces junio y Ciencias morales, de Martín Kohan.

fechas de nacimiento, la altura de cada jugador), el peso del bebé que nace en el asentamiento clandestino, el cálculo de nafta que el soldado gasta según su recorrido, los horarios que cumple diariamente, son solo algunos ejemplos. La presencia de estos números evoca toda una red de sentidos diseminados en el texto, actuando como testimonio plural de aquello que las palabras no logran o no pueden decir. Recuperando el planteo de Nicolás Rosa en "Estos textos, estos restos", dichos números pueden ser pensados como "lo faltante del discurso social, lo nodicho del discurso colectivizado, como borde o excrecencia de lo pleno lingüístico. Palabra muda [...] palabra-negada" (11) que supone un indicador figurado pero significativo de lo silenciado por la dictadura y de su perverso método de subjetivación según el cual las personas son consideradas números dispensables.

Una función similar parecen cumplir en Ciencias morales las postales que Francisco, el hermano de María Teresa, envía a su casa dando cuenta de los traslados de cuartel que debe cumplir como conscripto en el servicio militar (aunque en ningún momento se explicita cuál es su cargo ni cuáles son sus tareas, sí se insinúa que está cumpliendo el período de instrucción en las fuerzas del ejército). Se trata de imágenes acompañadas por textos en el reverso que se van abreviando a medida que Francisco es trasladado más al sur. En la primera, aparece una única y escueta frase: "No logro compenetrarme" (Kohan, Ciencias 21), seguida de su firma. Más adelante, María Teresa recibe otra postal acompañada nada más que por el nombre y apellido de su hermano. La siguiente entrega aparece firmada con un simple "Francisco", mientras que la última, enviada desde Comodoro Rivadavia, carece de escritura. Este progresivo borramiento de la palabra -que parece ir acompañado por una disolución de la identidad, en tanto el nombre propio se va desvaneciendo paulatinamente- también da cuenta de algo que no puede nombrarse; se trata de un texto que funciona como remanente de algo que subyace pero no termina de salir a la luz, y que, finalmente, se convierte en ausencia productiva. En rigor, como afirma Josefina Ludmer, "el residuo es, en realidad, no un resto sino un demás, un añadido y un suplemento (en) el texto" (49). El hecho de que el traslado hacia el sur vaya despojando a los mensajes de Francisco de 
lenguaje escrito supone una tensión en la que lo no dicho remite, de manera elíptica, a un acontecimiento velado pero palpable, es decir, a la guerra de Malvinas, en tanto el territorio de las islas es el más austral del país. Como contrapunto del silencio de Francisco, el narrador marca con insistencia este punto cardinal al referir a la posición geográfica en la que se encuentra el hermano de María Teresa, quien se va acercando cada vez más al foco del conflicto bélico: "Y es bien al sur. Más al sur de Bahía Blanca, que es donde estaba antes [...]; más al sur de Viedma, que es donde la provincia de Buenos Aires se acaba. Más al sur incluso de Trelew [...] al sur, bien al sur" (Kohan, Ciencias 155).

Estas alusiones a Malvinas son reforzadas por otras zonas de la novela en las que se habla de distintos aspectos vinculados con la guerra en un sentido general. Las elocuentes citas que María Teresa dicta a los alumnos del curso a su cargo para que trabajen durante la ausencia del profesor de Historia provienen de libros emblemáticos y referentes indiscutibles de esta temática: El arte de la guerra, de Sun Tsu; Del arte de la guerra, de Nicolás Maquiavelo; De la guerra, de Karl Von Clausewitz y Escritos militares, de M. Zedong. Asimismo, en uno de los capítulos (el tercer "Juvenilia") se menciona la Guerra del Paraguay y se analizan algunos de sus pormenores, mientras que durante la conversación que mantiene Biasutto con María Teresa en un café, el jefe de preceptores establece un paralelismo entre la vigilancia que las autoridades deben ejercer frente al descontrol de los alumnos y las tácticas que se implementan en batalla:

-Lea la historia, María Teresa, es lo más edificante. Cada vez que se gana una guerra, lo que sigue es la persecución de los últimos focos de resistencia del que perdió. Francotiradores, piquetes perdidos, los desesperados. Más se parece a una limpieza que a una batalla, ipero cuidado! Todavía forma parte de la guerra. (Kohan, Ciencias 151)

De este modo, la guerra constituye un tópico insistente que forma parte de un nuevo contraste entre lo no dicho, puesto que durante el transcurso de la novela 
CATEDRAL TOMADA: Revista de crítica literaria latinoamericana / Journal of Latin American Literary Criticism Una herida abierta. Tensiones y contrapuntos discursivos en Dos veces junio y Ciencias morales, de Martín Kohan.

no se refiere de manera puntual a lo que está sucediendo en Malvinas, y lo dicho, en tanto el último capítulo (aunque sin utilizar nunca el nombre de las islas) hace mención explícita al fin del conflicto bélico:

El 14 de junio de 1982 cae Puerto Argentino. El general argentino Mario Benjamín Menéndez, gobernador de las islas, firma la capitulación ante el general británico Jeremy Moore, comandante de las fuerzas victoriosas. Concluye así el conflicto armado, setenta y cuatro días después de producirse la invasión argentina. (Kohan, Ciencias 217)

El cénit de este contrapunto se hace presente en el capítulo en que los alumnos asisten al desfile conmemorativo del 25 de mayo y un periodista extranjero les pregunta “-Qu'est-ce que vous pensez de la guerre?”(Kohan, Ciencias 96). Este interrogante condensa los polos de lo manifiesto y lo oculto de manera paradigmática, puesto que si bien alude a una guerra -y el contexto histórico en que se desarrolla la novela sugeriría que se trata de Malvinas-, en ningún momento explicita si está refiriendo puntualmente al conflicto de las islas. A esto se suma el hecho de que la pregunta sea formulada en francés, lengua extranjera que desvía o difiere el contenido de ese interrogante que nunca recibe respuesta, en tanto los profesores "impartían la orden estricta de no mantener absolutamente ningún contacto con los representantes de prensa de los países extranjeros" (Kohan, Ciencias 96). Como sucede en otras zonas de la novela, el hermetismo del colegio, trasladado al exterior, opera en línea con el aislamiento al que se ve sometido el país, y la palabra, encorsetada por las restricciones del poder autoritario, se ve obturada, una vez más, por el silencio.

La presencia del fútbol en Dos veces junio parece funcionar en el mismo sentido que la guerra en Ciencias morales, es decir, como proyección de los mecanismos de la dictadura, como otro modo de intentar textualizar aquello de lo que "no se habla". Dos ejemplos claros aparecen en los capítulos "Ochenta mil" y "Mil novecientos setenta y ocho". En el primero, notamos cómo los gritos de gol a 
los que se alude en el fragmento VIII prácticamente se mimetizan con el "llanto de una criatura" que aparece, más adelante, en el fragmento X. En el segundo, por otra parte, la insistente repetición de la nómina de jugadores a lo largo del capítulo se revela como eco de los interrogadores que "le exigían los nombres, los nombres, los nombres" (Kohan, Dos veces 54) a la mujer torturada que mencionábamos más arriba. A estos inventarios onomásticos, se suman los de los caídos en combate que el protagonista lee en un diario al iniciar el epílogo. ${ }^{2}$ Lejos de revestir un carácter anecdótico, estos registros o inventarios de nombres adquieren una significación particular en el contexto en que se enmarca la novela, en tanto guardan una estrecha relación con una de las estrategias de persecución más nefastas de la dictadura: las listas negras. Estas listas, confeccionadas por el gobierno de facto, proscribían a personalidades de diferentes ámbitos cuya ideología o conducta fuera considerada peligrosa para el "bienestar de la nación" y llegaron a transformarse en listas de detenidos que, en muchos casos, se convirtieron en trágicas víctimas del terrorismo de estado. En un paralelismo notable con el discurso del régimen, caracterizado por la omisión, la ambigüedad recubre el discurso literario mediante la perífrasis y el rodeo. En Ciencias morales se habla de "las listas" pero sin especificar, una vez más, de qué listas se trata, aunque en reiteradas ocasiones María Teresa señala al señor Biasutto como autor de las mismas. Dentro de una institución que replica las pautas morales, ideológicas y operativas del sistema castrense, el accionar del jefe de preceptores es visto como un logro: "es una especie de héroe entre las autoridades del colegio; él hizo listas y ese mérito, aunque rumoreado, a nadie se le escapa" (Kohan, Ciencias 31). Sin embargo, cuando María Teresa quiere hablar del tema con Biasutto, él se muestra incómodo e intenta justificarse: "esa época fue realmente complicada para el país. La integridad de nuestra sociedad estaba amenazada, ¿sabe?, y hubo que actuar con absoluta energía” (Kohan, Ciencias

\footnotetext{
${ }^{2}$ La mención de Inglaterra como proveedor de información acerca de los muertos y desaparecidos en batalla, sumada al hecho de que el epílogo transcurre cuatro años después del argumento principal, permite recuperar (aunque no se la nombre) una alusión a la Guerra de Malvinas, lo cual supone una nueva puesta en acto de mecanismos discursivos elípticos.
} 
CATEdral Tomada: Revista de crítica literaria latinoamericana / Journal of Latin American Literary Criticism Una herida abierta. Tensiones y contrapuntos discursivos en Dos veces junio y Ciencias morales, de Martín Kohan.

149). Al apelar a argumentos similares a los que utilizan los defensores del régimen hegemónico -que, como indica Sarlo, "impone modelos de organización discursiva sobre presupuestos cuya verdad se presenta como autoevidente e indiscutible" (Sarlo 36)-, Biasutto vuelve a evocar el fantasma de la dictadura, cuya impronta discursiva eufemística y autolegitimadora sobrevuela la cuestión de las listas.

El contrapunto entre lo sugerido y lo explícito en relación con el modus operandi de la dictadura también es constante en Dos veces junio. Un ejemplo elocuente aparece nuevamente en el capítulo "Ochenta mil", en el que se construye una atmósfera densa plagada de referencias al silencio y al vacío, las cuales pueden proyectarse hacia la totalidad de la novela (desde el comienzo, el protagonista hace alusión al teléfono "colgado y mudo" que lo intimida). El soldado percibe, por un lado, "el silencio de la noche" y "el estadio callado", mientras que, por otro, nota que "la ciudad se había quedado vacía. Repentinamente vacía: ni un solo auto, ni un solo colectivo, ni una sola persona caminando, nadie por ningún lugar" (Kohan, Dos veces 60). Del mismo modo, apunta más adelante que "en esa calle, al igual que en las otras, no había nadie y todo estaba quieto" (Kohan, Dos veces 72), reforzando las ideas de desolación y ausencia que sobrevuelan el relato mediante la distribución de campos semánticos en los que se profundiza dicha percepción. En esta línea funcionan algunos adjetivos como "invisibles", "oscura" y "vacías" (Kohan, Dos veces 87) y sustantivos como "periferia", "suburbio" y "descampados" (que, además, se vinculan con lo marginal, es decir, lo "no oficial"). Algo similar ocurre en Ciencias morales el día en que María Teresa debe salir del colegio con los alumnos por los túneles secretos debido a que en la calle "se verifica algún desorden" (Kohan, Ciencias 31). Una vez que la preceptora entra en contacto con el exterior, comienza a notar algo similar a lo que advierte el soldado de Dos veces junio: "La calle luce tranquila. Demasiado tranquila, a decir verdad: es eso lo que tiene de extraña. Es la hora que corresponde al más intenso movimiento urbano y sin embargo aquí, en pleno centro, los autos escasean” (Kohan, Ciencias 35-36). Este énfasis en la súbita ausencia de los habitantes de Buenos Aires, puede ser leído como correlato de la desaparición de personas durante el gobierno de facto que tuvo 
lugar en la época en que se desarrolla la novela. No obstante, dicha lectura no se desprende de la obra en forma directa y explícita, puesto que, como venimos sosteniendo, ésta trabaja de manera constante con el eufemismo y la insinuación, con "estrategias de ciframiento", al decir de Beatriz Sarlo (46), que difieren la interpretación.

El episodio que cierra el capítulo "Ochenta mil”, de Dos veces junio, resulta particularmente ilustrativo en el marco de esta lógica sugestiva. El protagonista encuentra un anillo dorado con una inscripción en el anverso. En lugar de quedarse con el anillo para venderlo, apropiárselo o intentar hallar a su dueño, el soldado lo oculta:

el anillo, no sé por qué, lo tiré en el arenero de la plaza y después lo tapé a patadas con arena, primero lo tapé y después revolví todo con mis botas de soldado, hasta estar bien seguro de que no podría volver a encontrar ese anillo, ni siquiera en el caso imposible de que me pusiese a buscarlo. (Kohan, Dos veces 63)

Este frenético empeño por deshacerse del objeto, sumado al desconocimiento del motivo que lo lleva a actuar de esa manera, ubica al protagonista en un terreno difuso, de imprevisibilidad. El carácter indescifrable del gesto que lleva a cabo, sin embargo, se torna más claro al ser puesto en correlación con los aspectos discursivos que mencionamos anteriormente (campos semánticos, énfasis en determinadas constelaciones de sentido, reiteraciones conceptuales). En conjunto, todos estos factores permiten conjeturar que la actitud del soldado podría derivarse, o bien de un cargo de conciencia por complicidad que lo obliga a tomar esta decisión, o de un intento por desligarse de la situación producto del "no querer involucrarse" con la historia detrás del objeto. En cualquiera de ambos casos, el anillo evoca una realidad concreta que es silenciada y que, consecuentemente, pasa 
CATEDRAL TOMADA: Revista de crítica literaria latinoamericana / Journal of Latin American Literary Criticism Una herida abierta. Tensiones y contrapuntos discursivos en Dos veces junio y Ciencias morales, de Martín Kohan.

al plano de la clandestinidad, de lo oculto. ${ }^{3}$ Algo similar sucede en un capítulo anterior titulado "Veinticinco millones", en el que los eufemismos apuntan, sin nombrarlo, al accionar de la dictadura militar:

[...] había ratas. Ahora que las calles estaban vacías, se las podía oír ahí adentro. En el silencio de la ciudad sin gente, [...] sonaban como los pasos de una persona que deambulara sin ningún lugar adonde ir. Prestando un poco más de atención, se alcanzaba a percibir los chillidos de las ratas. Se parecían mucho a los gemidos de una persona que quiere y no puede contener un sollozo. Eran muchas las ratas [...] o acaso, habiendo ratas, había también gatos que las perseguían. (Kohan, Dos veces 70 -la negrita es nuestra-)

La correlación que se establece entre la figura de las ratas y la de "una persona", sumadas al contexto en el que se desarrolla la historia, sugiere, a partir de las imágenes de la persecución y los gemidos, todo un espectro vinculado a las prácticas de seguimiento y tortura llevadas a cabo por los militares durante la última dictadura en Argentina. La imagen del gato cazando al ratón, por su parte, es también homologada con el accionar de un ser humano, al comparar el golpe del felino contra una pared con "una persona que daba una trompada en una pared" (Kohan, Dos veces 70). Al constante intercambio entre el modo de operar de los animales y los seres humanos, se suma la insistente y poderosa imagen de la mujer que, desde el principio de la novela, está siendo interrogada -casi no se habla de "tortura"; la vejación se ejerce pero no se nombra- y que se desplaza a lo largo de toda la historia. Esa mujer secuestrada, prisionera omnipresente en el relato, parece encarnar la figura de la persona sollozante a la que refiere el último pasaje citado gracias al despliegue de un discurso alusivo/elusivo que, mediante cruces y

\footnotetext{
${ }^{3}$ Como afirma Gramuglio, "ese episodio agudo de barbarización política y degradación del Estado no hubiera sido posible sin el compromiso, la adhesión, la conformidad de muchos" (14) que contribuyeron a sostener, por complicidad u omisión, el régimen totalitario.
} 
resonancias constantes, construye una red de referencias e inferencias vinculadas con el proceder de los militares. Al decir de Sarlo, el discurso adopta "la forma de la elipsis, la alusión y la figuración como estrategias para el ejercicio de una perspectiva sobre la diferencia" (35) que permite resquebrajar el unitarismo discursivo de la hegemonía dictatorial. Un recurso de similares características es utilizado en Ciencias morales cuando se relata cómo María Teresa se dispone a caminar por la calle luego de haber salido del colegio utilizando los túneles secretos. El narrador da cuenta del estado de incertidumbre que envuelve a la preceptora y la atmósfera cargada de oscuridad y turbación que la rodea:

Si tuviese que distinguir al menos una señal que provenga de lo que está pasando, no podría hacerlo. Y sin embargo no cabe duda de que el cielo de la ciudad se ha ensombrecido, y que cae un acento espeso sobre la noche que se acerca. No es posible indicar con nitidez de dónde surge esa especie de congoja, pero se la puede tocar lo mismo que el aire. (Kohan, Ciencias 36)

La imposibilidad de precisar la naturaleza de los acontecimientos que ocurren en la calle choca con la intuición de que algo está efectivamente sucediendo. Se genera así una oscilación entre el saber y el ignorar atravesada, una vez más, por la sugerencia y lo elidido. El accionar de la dictadura, sin ser manifiesto, deja una huella perceptible, y aunque una "retórica de la elipsis" (Di Meglio, "Dos veces..." 2) se imponga por sobre lo abiertamente expresado, los rastros de dicha operatoria perduran en el discurso.

Como puede observarse a partir del análisis precedente, ambas novelas se encuentran atravesadas por múltiples factores de tensión y contrapunto que se despliegan tanto en el plano del enunciado como en el de la enunciación. La carga ideológica del lenguaje, de la mano con los recursos y estrategias discursivas a los que hemos hecho alusión, dan lugar a una narrativa que, en sintonía con lo que Sarlo señala acerca del discurso literario durante la dictadura, intenta "más que 
CATEDRAL TOMADA: Revista de crítica literaria latinoamericana / Journal of Latin American Literary Criticism

Una herida abierta. Tensiones y contrapuntos discursivos en Dos veces junio y Ciencias morales, de Martín Kohan.

proporcionar respuestas articuladas y completas, rodear ese núcleo resistente y terrible que podía denominarse lo real" (35). En este sentido, las dos obras funcionan como espacios de confluencia en los que circulan discursos sociales diversos y perspectivas contrastivas que, lejos de pretender convocar una integridad totalizante, complejizan los sentidos en pugna, dinamizando y pluralizando la narración. Revisitar esa época, redescubrir ese pasado, mantener viva la memoria parecen ser los objetivos que impulsan a Martín Kohan a escribir estas novelas. Así, la herida que no cicatriza encuentra en la literatura un espacio de reflexión crítica en el que perduran y resisten los vestigios de uno de los acontecimientos más funestos de nuestra historia.

\section{Bibliografía}

Altamirano, Carlos y Sarlo, Beatriz. Conceptos de sociología literaria. Buenos Aires, CEAL, 1980. . Literatura/Sociedad. Buenos Aires, EDICIAL, 2001.

Bajtin, Mijail. Estética de la creación verbal. México, Siglo XXI, 1998.

Bajtin, Mijail. Problemas de la poética de Dostoievksy. México, Siglo XXI, 1986.

Coira, María. "Memoria y trauma en tres novelas de Martín Kohan”, en María Coira , Rosalía Baltar y Carola Hermida (comps.). Escenas interrumpidas 11. Imágenes del fracaso, utopías y mitos de origen en la literatura nacional. Buenos Aires, Katatay, 2012; 73-86. 
Di Marco, José. "Ficción y memoria en la narrativa argentina actual: la escritura como táctica" [En línea]. $V^{\circ}$ Congreso Internacional Orbis Tertius de Teoría y Crítica Literaria, 13 al 16 de agosto de 2003, La Plata, 2003. Polémicas literarias, críticas y culturales.

http://www.fuentesmemoria.fahce.unlp.edu.ar/trab_eventos/ev.11/ev.11.pdf

Di Meglio, Estefanía. “Dos veces junio de Martín Kohan.

Una mirada desde lo alternativo" [En línea]. IV Congreso Internacional

Celehis de Literatura, 7 al 9 de noviembre de 2011, Mar del Plata, 2011.

http://www.mdp.edu.ar/humanidades/letras/celehis/congreso/2011/actas/pon encias/dimeglio.html

- "Ciencias morales o la confrontación de lenguajes e identidades.

Silencios, discursos e identidades en pugna" [En línea]. VI Jornadas

Internacionales de Filología y Lingüística y Primeras de Crítica Genética,

5 al 7 de agosto de 2013, La Plata, 2013. "Las lenguas del archivo".

http://jornadasfilologiaylinguistica.fahce.unlp.edu.ar/vi-jornadas-1/actas-

2013/DiMeglio.pdf

Gramuglio, María Teresa. "Políticas del decir y formas de la ficción. Novelas de la dictadura militar" en Punto de vista N $^{\circ} 74,2002$; 9-14.

Kohan, Martín. Dos veces junio. Buenos Aires, Debolsillo, 2013 [2002].

Kohan, Martín. Ciencias morales. Barcelona, Anagrama, 2014 [2007].

Ludmer, Josefina. "El resto del texto" (1973) en AA.VV. Literal. (Edición fascimilar) Buenos Aires, Biblioteca Nacional, 2011.

Rodríguez Montiel, Emiliano. "La «historia argentina» en la narrativa de Martín Kohan: adyacencia, reescritura y pormenorización” [En línea]. I $V^{\circ}$ Congreso Internacional Cuestiones Críticas, 30 de septiembre al 2 de octubre de 2015, Rosario, 2015. Polémicas literarias, críticas y culturales. http://www.celarg.org/int/arch_publi/rodriguezmontielcc2015.pdf 
CATEdral Tomada: Revista de crítica literaria latinoamericana / Journal of Latin American Literary Criticism

Una herida abierta. Tensiones y contrapuntos discursivos en Dos veces junio y Ciencias morales, de Martín Kohan.

Rosa, Nicolás. "Estos textos, estos restos" en Los fulgores del simulacro.

Universidad Nacional del Litoral, Cuadernos de extensión universitaria, $\mathrm{n}^{\circ}$

15,$1987 ; 9-18$.

Sarlo, Beatriz. "Política, ideología y figuración literaria"en Balderston y otros:

Ficción y política. La narrativa argentina durante el proceso militar.

Buenos Aires-Madrid, Alianza, 1987; 30-59.

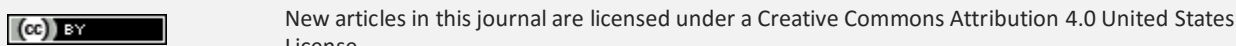
License.

ULIS D. This site is published by the University Library System, University of Pittsburgh as part of its D-Scribe. Digital Publishing Program and is cosponsored by the University of Pittsburgh Press. 